\title{
A Simple Nonlinear Model of the Switched Reluctance Motor
}

\author{
Vladan Vujičić and Slobodan N. Vukosavić
}

\begin{abstract}
The paper presents a simple nonlinear model of the switched reluctance motor (SRM) which requires a minimum of precalculated or measured input data. Therefore, it is convenient for use in earlier stage of SRM design in order to minimize time for finding optimal configuration. Moreover, it is shown that this model produces accurate torque shape for given current, and accurate flux linkage-current relationships. This also provides reliable results in dynamic regime. The simulation and experimental results are compared for available three-phase 6/4 motor.
\end{abstract}

Index Terms-Modeling, reluctance motor.

\section{INTRODUCTION}

$\mathbf{T}$ HE SRM has very simple, cost effective construction, but determining its performances is difficult because of highly nonlinear relationship between the torque and the excitation current [1]. The nonlinearity is greatly affected by intense saturation of the corners of partially overlapping stator and rotor poles. The energy conversion principles show that accurate calculation of produced torque may be obtained from the relationships between the phase current i), flux-linkage $(\Psi)$ and angular rotor position $(\theta)$. Therefore, most of the existing SRM models are based on previously provided magnetization curves $(\Psi-i)$ for a number of rotor position angles [2]-[4]. These magnetization characteristics can be obtained from measurements on existing motor or from sufficiently precise numerical calculations such as finite element (FE) analysis [5], [6] or some other method [7]. Such models are not suitable for computer-aided design (CAD) of the SRM drive because large time is needed to calculate necessary large numbers of magnetization $(\Psi-i)$ points for any variation of the motor geometry.

The performances of SRM drive strongly depend on applied control. The drive system, comprising signal-processing, power converter and motor must be designed as a whole for the specific application. Therefore, a model suitable for CAD must be not only fast, but also it must be able to predict the static and the dynamic characteristics with enough accuracy. On an existing SRM drive such model can be used to optimize control parameters.

Some models, as those based on "gage curve" [8], [9], use empirical knowledge and need only a few precalculated points of the magnetization $(\Psi-i)$ curves. The gage curve models have ability to include into account all main nonlinearities. However,

Manuscript received July 21, 1999.

V. Vujičić is with the Department of Electrical Engineering, University of Montenegro, 81000 Podgorica, Montenegro, Yugoslavia.

S. N. Vukosavić is with the Department of Electrical Engineering, University of Belgrade, 11000 Belgrade, Serbia, Yugoslavia.

Publisher Item Identifier S 0885-8969(00)10110-X. they are unable to include effects of mutual interaction between two or more simultaneously excited phases, which are important in designing SRM drive with four or larger number of motor phases [10], [11].

A number of nonlinear SRM models, using magnetic theory [12], [13], have been developed. In [12] a magnetic circuit concept is used for computing SRM's mean torque. Analytical equations, which include the effect of iron saturation, are developed in [13]. These equations can well predict magnetization $(\Psi-i)$ curves and static torque. However, where there is no pole overlap, the model in [13] does not include saturation. Thus, the greatest difficulty for this model occurs when the rotor and stator pole overlap just begins.

In this paper a simple nonlinear model of the SRM is presented. This model uses equivalent magnetic circuit of the motor as a set of reluctances linked in series and in parallel. These reluctances have physical meaning and are found from fundamental and some empirical considerations and knowledge. The model allows including into account mutual interaction between phases as well as the nonlinearities. As an input it requires the motor geometry, some specific points of iron core B-H curve, and only one precalculated or measured magnetization $(\Psi-i)$ point. For more accurate simulation the model allows fitting by using some other magnetization $(\Psi-i)$ points, and also allows further improvements.

\section{BASIC CONCEPT}

In determining the basic equation which gives relationship between flux linkage $(\Psi)$, phase current $i$ ) and rotor position $(\theta)$ it is assumed that reluctance of SRM magnetic circuit can be represented by five reluctances linked in series. Than, this relationship can be expressed as:

$$
i=\frac{\Psi}{N^{2}} \sum_{j=0}^{4} R_{j}
$$

where $N$ is number of turns per phase, and reluctances $R_{j}$ are defined as:

$$
R_{j}=\frac{l_{j}}{\mu_{j} A_{j}},
$$

where $l_{j}, \mu_{j}$ and $A_{j}$ are the length, permeability and the cross section area, respectively, of the corresponding part of the flux path, as shown in Fig. 1. All parts of reluctances $R_{j}(j=0,1, \cdots, 4)$ consist of two identical portions. The reluctances $R_{1}, R_{2}, R_{3}$ and $R_{4}$ are associated with the stator yoke, two stator poles, rotor yoke, and two rotor poles, respectively. The reluctance $R_{o}$ includes the air parts and narrow 


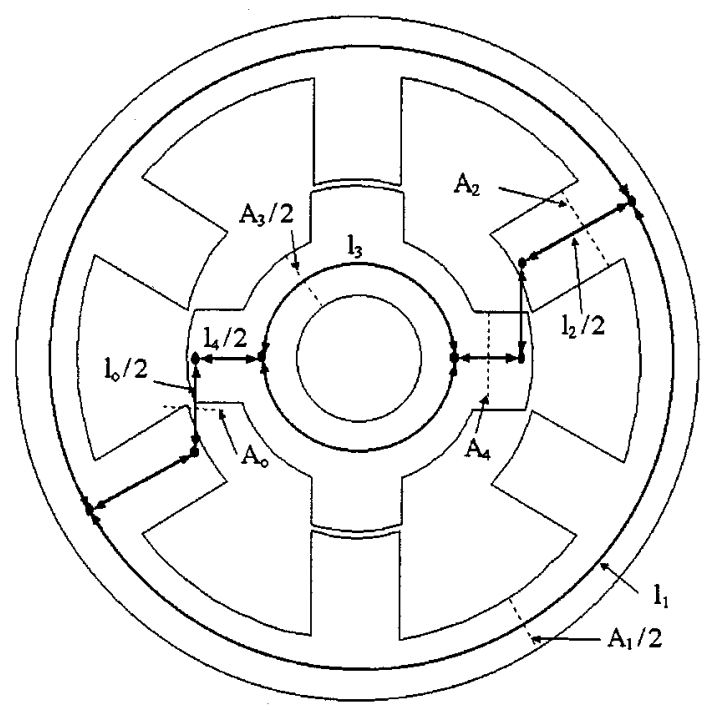

Fig. 1. Defining equivalent reluctances of magnetic circuit of the SRM (example of $6 / 4$ motor).
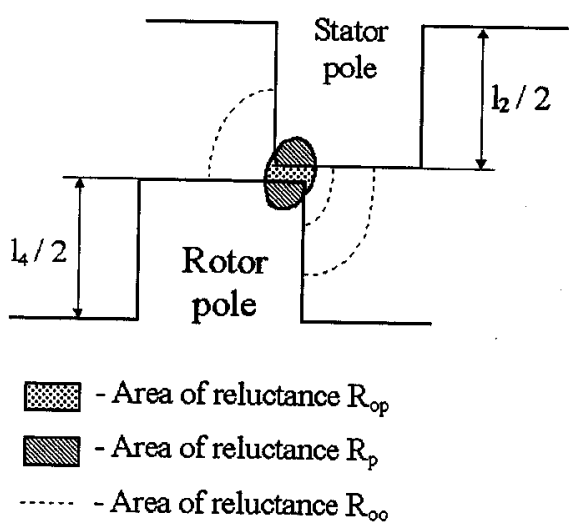

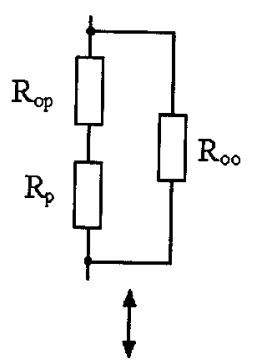

$\prod_{1} R_{0}$
Fig. 2. Defining reluctance $R_{o}$.

highly saturable parts of stator and rotor pole corners (see Fig. 2). This reluctance varies with rotor position $(\theta)$ and with the flux density (B) while the other reluctances vary only with the flux density. Precise determination of reluctance $R_{O}$ is very difficult. In the proposed model it is represented in the form of two reluctances in series and one in parallel with them, as shown in Fig. 2. Thus, reluctance $R_{O}$ can be found from:

$$
\frac{1}{R_{o}}=\frac{1}{R_{o o}}+\frac{1}{R_{o p}+R_{p}} .
$$

Reluctance $R_{p}$ in (3) stands for the rotor and the stator pole corners, which come into saturation earlier than the other iron parts of the motor. This effect is the consequence of the small air gap in overlapped portion of stator and rotor poles, and the large lengths on the other air paths through which flux "flows." The reluctance of the airgap is included by $R_{o p}$. When the flux has a relatively small values, it almost entire flows through the parts with reluctances $R_{o p}$ and $R_{p}$. However, with the greater value of the flux, the flux density in $R_{p}$ increases, and the value of reluctance $R_{p}$ increases, too. Therefore, the influence of the other flux paths becomes significant. All the other air parts for the flux flowing are represented by reluctance $R_{o o}$.

In order to simplify further considerations, the expression (1) can be written as:

$$
i(\theta, \Psi)=\frac{\Psi R_{o}}{N^{2}}+\frac{\Psi}{N^{2}} \sum_{j=1}^{4} R_{j}=i_{o}(\theta, \Psi)+i_{f e}(\Psi),
$$

where current $i_{o}$ is related to the reluctance $R_{o}$ and current $i_{f e}$ is related to the other reluctances.

In the proposed model, for the cases when only one phase is exited, the entire flux flows through the paths $R_{j}$ ( $j=0$ to 4 ), i.e. the leakage flux is neglected. The results of FE analysis show that the leakage flux has a small value [10], [11], though its influence is not negligible when the saturation level of the iron core is higher. In the proposed model this phenomena are included indirectly, which is explained in the latter section.

If more than one phase is excited, the parts of the reluctances $R_{1}$ and $R_{4}$ must be divided in the portions with different fluxes. For example, when the two phases are simultaneously excited, the fluxes in these parts are equal to the sum or the difference of the phase fluxes, as shown in [10], [11]. Thus, our model can be easily applied for multiphase regime.

\section{TOWARDS THE DYNAMIC MODEL OF THE SRM}

\section{A. Some Simplifications in Determining Reluctance $R_{O}$}

From (2) and from Fig. 2 it is obvious that for calculation of reluctance $R_{o}$ three effective parameters must be known. However, if, for reluctance $R_{o}$, we take $\mu=\mu_{o}$ and $l=2 g$ ( $g$-the air gap length), only the effective cross section area $A_{o}$ will be the unknown variable:

$$
R_{o}=\frac{2 g}{\mu_{o} A_{o}} .
$$

Thus, the problem of calculation of the reluctance $R_{0}$ is reduced to the determination of the effective area $A_{O}$ which is function of flux linkage $(\Psi)$ and rotor position $(\theta)$.

On the other hand, reluctances $R_{o o}, R_{o p}$, and $R_{p}$ can be written as: $R_{o o}=l_{o o} /\left(\mu_{o o} A_{o o}\right), R_{o p}=l_{o p} /\left(\mu_{o p} A_{o p}\right)$ and $R_{p}=l_{p} /\left(\mu_{p} A_{p}\right)$, where $l_{o o}, l_{o p}$ and $l_{p}$ are effective lengths, $A_{o o}, A_{o p}$ and $A_{p}$ are effective cross section areas, and $\mu_{o o}, \mu_{o p}$ and $\mu_{p}$ are the relevant permeabilities. It is obvious that $\mu_{o o}=\mu_{o p}=\mu_{o}, l_{o p}=2 g$, and that the areas $A_{o p}$ and $A_{p}$ are approximately equal to the cross section area of overlapping rotor and stator poles (see Fig. 2). Therefore, if we take $A_{o p}=A_{p}$, and, in order to reduce number of variables, we take $l_{o o}=2 g$, than, using (3) and (5), we obtain:

$$
A_{o}=A_{o o}+\frac{A_{p}}{1+\xi \frac{\mu_{p o}}{\mu_{p}}},
$$

where $\mu_{p o}$ is the initial permeability of $\mu_{p}$, and $\xi=$ $l_{p} \mu_{o} /\left(2 g \mu_{p o}\right)$. Thus, the problem of determination of reluctance $R_{o}$ is reduced to the determination of variables $A_{p}, A_{o o}, \xi$, and $\mu_{p}$. Note that quantities $A_{p}$ and $A_{o o}$ depend upon the rotor position $\theta$ only. 


\section{B. Further Development of the Model}

The saturation in the area of reluctance $R_{p}$ is modeled by the Fröhlich curve:

$$
B_{p}=\frac{B_{p m} H_{p}}{\frac{B_{p m}}{\mu_{p o}}+H_{p}} .
$$

Here $B_{p m}$ is the maximum flux density with a typical value of $2 T$ for most commonly used materials. From $B_{p}=\Psi_{p} /\left(N A_{p}\right)$, where $\Psi_{p}$ is the portion of flux linkage $\Psi$ which flows through the areas with reluctances $R_{p}$ and $R_{o p}$, the permeability $\mu_{p}$ can be expressed from (7) as:

$$
\mu_{p}=\frac{B_{p}}{H_{p}}=\mu_{p o}\left(1-\frac{\Psi_{p}}{B_{p m} N A_{p}}\right)
$$

The unknown variable $\Psi_{p}$ can be found from the equation:

$$
R_{o o}\left(\Psi-\Psi_{p}\right)=\left(R_{p}+R_{o p}\right) \Psi_{p}
$$

Now, combining equations (4)-(6), (8) and (9), the relationship between flux linkage $\Psi$, rotor position $\theta$ and current $i_{o}$ can be expressed as:

$$
i_{o}=c_{o \tilde{5}}\left[\left(1-c_{o 1}\right) \psi-c_{o 1} c_{o 2}+c_{o 1} \sqrt{\left(\psi-c_{o 3}\right)^{2}+c_{o 4}^{2}}\right],
$$

where: $c_{o 1}=A_{p} /\left[2\left(A_{p}+A_{o o}\right)\right], c_{o 2}=B_{p m} N\left[A_{p}+(1+\right.$ $\left.\xi) A_{o o}\right], c_{o 3}=B_{p m} N\left[A_{p}+(1-\xi) A_{o o}\right], c_{o 4}^{2}=c_{o 2}^{2}-c_{o 3}^{2}=$ $4 \xi B_{p m}^{2} N^{2} A_{o o}\left(A_{p}+A_{o o}\right)$, and $c_{o 5}=2 g /\left(\mu_{o} N^{2} A_{o o}\right)$. Coefficients $c_{o k}(k=1,2, \cdots, 5)$ are functions of only three variables $\left(A_{o o}, A_{p}\right.$ and $\left.\xi\right)$. Hence, determination of current $i_{o}$ is further simplified.

For the small flux linkage $(\Psi)$, the reluctance $R_{o}$ is dominant due to a high permeability of nonsaturated iron in all the other parts of magnetic circuit. Permeability $\mu_{p}$ has also very high values and, therefore, reluctance $R_{o}$ is almost independent of flux linkage $(\Psi)$. As a consequence we can define the area $A_{i o}=A_{o}(\theta, \Psi \cong 0)$ as function only of rotor position $(\theta)$. Referring to (4) and (5), the area $A_{i o}$ has the same shape as unsaturated phase inductance. Experience from previous works [3], [8] shows that this shape resembles Fig. 3. A minimum value $A_{\text {min }}$ of the area $A_{i o}$ is at the unaligned rotor position $\left(\theta_{u n}\right)$, and the maximum value $A_{\max }$ is attained at the aligned rotor position $\left(\theta_{a l}\right)$. The constant $A_{\min }$ can be determined from the unaligned inductance $\left(L_{u n}\right)$ as:

$$
A_{\min }=2 g L_{u n} /\left(N^{2} \mu_{o}\right) \text {. }
$$

The constant $A_{\max }$ can be determined in a similar way:

$$
A_{\max }=2 g L_{\text {oal }} /\left(N^{2} \mu_{o}\right) \text {, }
$$

where $L_{o a l}$ is unsaturated inductance at the aligned position $\left(\theta_{a l}\right)$. The ratio $A_{\max } \mu_{o} /(2 g)$ is the airgap permeance at the aligned position $\left(\theta_{a l}\right)$, and, therefore, the constant $A_{\max }$ must be somewhat larger than the cross section area of stator pole $\left(A_{2}\right)$, [14]. For further simplification and reduction in the number of necessary magnetization $(\Psi-i)$ points, the approximate value is used:

$$
A_{\max }=A_{\min }+A_{2},
$$

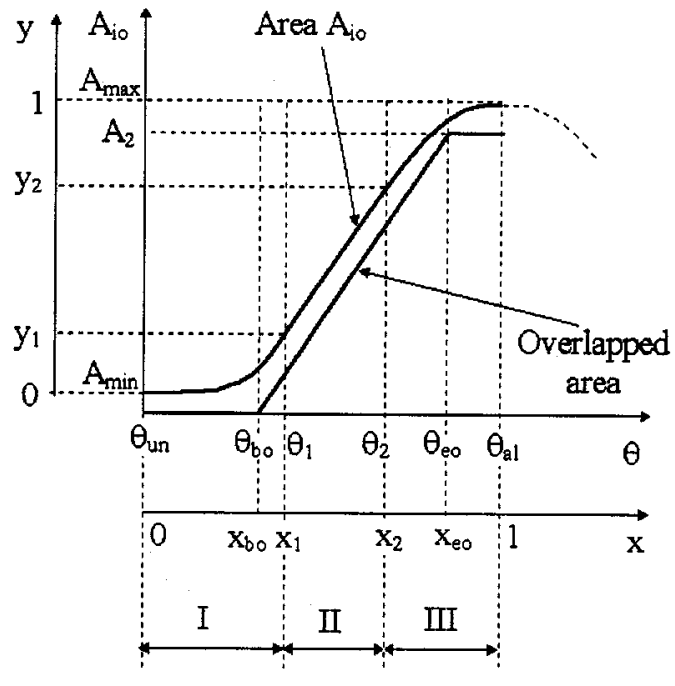

Fig. 3. Shaping area $A_{i o}$.

This approximation does not differ much from the actual $A_{\max }$, and, for simplification, it allows:

$$
A_{p}=A_{\text {io }}-A_{\min } \text {. }
$$

For the case $\Psi \cong 0$ we can use $\mu_{p}=\mu_{p o}$, and $A_{o}=A_{i o}$ in (14). Thus, by combining (6) and (14) the area $A_{o o}$ can be determined as:

$$
A_{\circ o}=A_{\min }+\xi A_{i o} /(1+\xi) .
$$

Regarding (14) and (15), coefficients $c_{o k}(k=1,2, \cdots, 5)$ in (10) depend only on two variables $A_{i o}$ and $\xi$.

We shall now introduced the normalized value $y$ of the area $A_{i o}$ :

$$
y=\left(A_{i o}-A_{\min }\right) /\left(A_{\max }-A_{\min }\right),
$$

and the normalized value $x$ for current rotor position $(\theta)$ :

$$
x=\left(\theta-\theta_{u n}\right) /\left(\theta_{a l}-\theta_{u n}\right) .
$$

Dividing the rotor position $(\theta)$ into three regions, from the unaligned $\left(\theta_{u n}\right)$ to the aligned $\left(\theta_{a l}\right)$ position (see Fig. 3), we shall describe $A_{i o}$ as:

$$
y(x)=\left[\begin{array}{ccc}
a_{1} x^{p}+b_{1} x^{p-1} & \vdots \quad 0 \leq x<x_{1} \\
y_{1}+k_{a}\left(x-x_{1}\right) & \vdots \quad x_{1} \leq x \leq x_{2} \\
a_{2}(1-x)^{q}+b_{2}(1-x)^{q-1}+1 & \vdots \quad x_{2}<x \leq 1
\end{array}\right.
$$

where $a_{1}, a_{2}, b_{1}, b_{2}, p$ and $q$ are constants, $x_{1}$ and $x_{2}$ are normalized boundary angles between rotor position regions, and $y_{1}$ is value of $y$ for $x=x_{1}$ (see Fig. 3). Function $y(x)$ and its first derivative $(d y / d x)$ must be continuous and smooth in order to get smooth calculated torque. This is consequence of the torque equation including the area $A_{i o}$ and its derivative $\left(d A_{i o} / d \theta\right)$, as it is shown in later section. The set of functions in (18) allows that this requirements are satisfied if constants $a_{1}, a_{2}, b_{1}, b_{2}, p$ and $q(p$ and $q$ must be grater than 2$)$ have values: $a_{1}=-k_{a}(p-$ $2) /\left(p x_{1}^{p-1}\right), b_{1}=k_{a} / x_{1}^{p-2}, p=2 k_{a} x_{1} / y_{1}, q=2 k_{a}(1-$ $\left.x_{2}\right), a_{2}=k_{a}(p-2) /\left[p\left(1-x_{2}\right)^{p-1}\right], b_{2}=-k_{a} /\left(1-x_{2}\right)^{p-2}$. In the region II $\left(x_{1} \leq x \leq x_{2}\right)$ the normalized area $y$ is linear function of normalized angle $x$. The constant $k_{a}$ should 
equalize the gradient of $A_{p}\left(d A_{p} / d \theta\right)$ with the gradient of the actual overlapping area, i.e.: $k_{a}=1 /\left(x_{e o}-x_{b o}\right)$, where $x_{b o}$ and $x_{e o}$ are normalized angles corresponding to the position of the starting $\left(\theta_{b o}\right)$ and full overlapping $\left(\theta_{e o}\right)$ of rotor and stator poles (see Fig. 3). Experiments show that area $A_{p}$ has somewhat greater value than actual area of mechanical overlapping (about five percent of stator area $\left.A_{2}\right)$, i.e.: $y_{1}=k_{a}\left(x_{1}-x_{b o}\right)+k_{b}$, where $k_{b}$ has value from 0.045 to 0.05 for various motor constructions. The best results are obtained if normalized angle $x_{1}$ and $x_{2}$ correspond to the position of about $1 / 10$ and $2 / 3$ of real overlapping area, i.e.: $x_{1}=x_{b o}+\left(x_{e o}-x_{b o}\right) / 10$ and $x_{2}=x_{e o}-\left(x_{e o}-x_{b o}\right) / 3$.

All constants in (18) are now determined, and the area $A_{i o}$ can be easily obtained from (16) as:

$$
A_{i o}=y\left(A_{\max }-A_{\min }\right)+A_{\min } .
$$

Thus the coefficients $c_{o k}(k=1,2, \cdots, 5)$ in (10) are entirely determined from (11), (13)-(15), (17)-(19). The only unknown variable is $\xi$ which is introduced in (6). It depends on the iron magnetic characteristics, rotor position, size of flux linkage and airgap lengths, and it must be $\xi \ll 1$. Simulation results prove that this factor can be used as a small constant. Furthermore, their sensitivity to $\xi$ changes is found to be rather weak. The best results are obtained when parameter $\xi$ has value within 0.02 and 0.05 , for the most types of the motor.

\section{Determining the Reluctance of the Iron}

For determining the $i_{f e}$ in (4), the reluctances $R_{1}, R_{2}, R_{3}$ and $R_{4}$ in (2) must be found from the flux linkage $\Psi$. These reluctances represent the overall iron reluctance excluding the area of the reluctance $R_{p}$. The lengths $l_{j}$ and the areas $A_{j}(j=1$ to 4) in (2) depend on the SRM construction and are shown in Figs. 1 and 2 . Each parameter $\mu_{j}$, corresponding to the reluctance $R_{j}(j=1$ to 4$)$, can be calculated from $\mathrm{B}-\mathrm{H}$ curve for which we used the form:

$$
\frac{H_{j}}{H_{s}}=\gamma \frac{B_{j}}{B_{s}}+(1-\gamma)\left(\frac{B_{j}}{B_{s}}\right)^{\alpha},
$$

where $H_{j}$ and $B_{j}$ are respectively field intensity and flux density in the area of reluctance $R_{j}$, and $\gamma, \alpha, H_{s}$ and $B_{s}$ are constants defining the $\mathrm{B}-\mathrm{H}$ curve. The point $\left(B_{s}, H_{s}\right)$ on the curve should have the value so that for the flux density $B_{j}$ smaller than $B_{s}$, the reluctance $R_{j}(j=1,2,3,4)$ is relatively low in comparison with reluctance $R_{o}$. Also, when the flux density $B_{j}$ tends to reach the value $B_{s}$, the influence of saturation effect becomes significant (typical value of $B_{s}$ is within $1.1 \mathrm{~T}$ and 1.3T). Parameter $\gamma$ has value from $0.6-0.7$ for the most commonly used iron. If we chose exponent $\alpha$ so that (20) matches well the real B-H curve, we will get poorer results for magnetization $\Psi-i$ curves in the saturation region due to the leakage flux becoming more pronounced. Experiments show that this could be overcome by taking somewhat smaller value for $\alpha$ (value of $\alpha$ varies from 7-13 for different irons and motor constructions). In the case that one $\Psi-i$ point in the saturation region for the aligned position $\theta_{a l}$ is known from the measurement or numerical calculation, the coefficient $\alpha$ can be determined more precisely.
From (20) we find permeability $\mu_{j}$ as $1 / \mu_{j}=H_{j} / B_{j}$ with $B_{j}=\Psi /\left(N A_{j}\right)$. Thus, from (2) and (4) the current $i_{f e}$ is found as:

$$
i_{f e}=c_{f e 1} \Psi+c_{f e 2} \Psi^{\alpha}
$$

where:

$$
c_{f e 1}=\sum_{j \geq 1} \frac{l_{j} \gamma H_{s}}{B_{s} N^{2} A_{j}}, \quad c_{f e 2}=\sum_{j \geq 1} \frac{l_{j}(1-\gamma) H_{s}}{B_{s}^{\alpha} N^{\alpha+1} A_{j}^{\alpha}} .
$$

The phase current $i$ in (4) is now determined from (10) and (20). Note that for the multiphase operation, the equation (20) has to be appropriately changed as it is mentioned in Section II. However, when the current overlapping between phases is relatively low, as it is the case in the most 6/4 SRM drives, this equation can be used in original form (20).

\section{Calculation of Torque}

Instantaneous torque can be calculated by defining magnetic co-energy $W_{m}^{\prime}$ as a function of rotor position $\theta$ and phase current $i$, or by defining magnetic energy $W_{m}$ as a function of rotor position $\theta$ and flux linkage $\Psi$. Referring to (4), magnetic energy $W_{m}$ can be obtained as:

$$
W_{m}=\int i d \Psi=\int i_{o} d \Psi+\int i_{f e} d \Psi=W_{m o}+W_{m f e} .
$$

In (22) the energy $W_{m o}$, related to the current $i_{o}$, varies with rotor position $\theta$ and flux linkage $\Psi$. Second term $W_{m f e}$, related to the current $i_{f e}$, varies only with flux linkage $\Psi$. As consequence, the produced torque $T$ is determined as:

$$
T=-\frac{\partial W_{m}}{\partial \theta}=-\frac{\partial W_{m o}}{\partial \theta}-\frac{\partial W_{m f e}}{\partial \theta}=-\frac{\partial W_{m o}}{\partial \theta} .
$$

Energy $W_{m o}=\int i_{o} d \psi$ can be determined by substituting $i_{o}$ from (10), which gives:

$$
\begin{aligned}
& W_{m o}=c_{o 5}\left[\frac{1-c_{o 1}}{2} \psi^{2}-c_{o 1} c_{o 2} \psi+\frac{c_{o 1}}{2}\left(\psi-c_{o 3}\right)\right. \\
& \cdot \sqrt{\left(\psi-c_{o 3}\right)^{2}+c_{o 4}^{2}}+\frac{c_{o 1} c_{o 2} c_{o 3}}{2}+\frac{c_{o 1} c_{o 4}^{2}}{2} \\
& \left.\cdot \ln \left(\frac{\psi-c_{o 3}+\sqrt{\left(\psi-c_{o 3}\right)^{2}+c_{o 4}^{2}}}{c_{o 2}-c_{o 3}}\right)\right] \text {, }
\end{aligned}
$$

where coefficients $c_{o k}(k=1,2, \cdots, 5)$ are defined in (10). These coefficients are functions of the area $A_{i o}$, and this area is the function of rotor position $\theta$. Thus, the equation (24) can be written as:

$$
T=-\frac{\partial W_{m o}}{\partial A_{i o}} \frac{d A_{i o}}{d \theta} .
$$

Equation (24) shows that for a smooth torque, the $A_{i o}$ derivative $d A_{i o} / d \theta$ must be a smooth function of rotor position $\theta$, as provided by (18).

The torque can be obtained by solving (25), or approximately as:

$$
T=-\frac{W_{m o}(\psi, \theta)-W_{m o}(\psi, \theta-\Delta \theta)}{\Delta \theta},
$$

where $\Delta \theta$ is a small step in the calculations of rotor position $\theta$. 


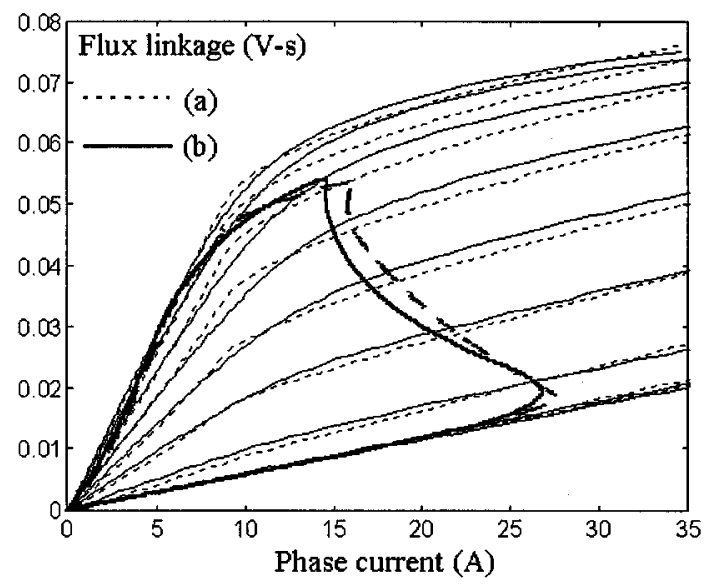

Fig. 4. Magnetization curves (from unaligned to aligned positions with step $5^{\circ}$ ) and energy conversion loops for motor from [1], obtained by (a) model described in [8] and by (b) new model.

\section{E. Concluding the Section III}

Concluding this section, let us point out that our dynamic modeling of SRM is based on two variables i.e. rotor position $\theta$ and flux linkage $\Psi$, which is calculated from the equation:

$$
\psi=\int_{0}^{t}(v-R i) d t
$$

where

$v \quad$ is the voltage applied to the phase winding,

$R \quad$ is the phase resistance, and

$i \quad$ is the phase current obtained from (4) for previous rotor position $\theta-\Delta \theta$.

For starting the SRM simulation, only the unaligned inductance $L_{u n}$ is needed in order to obtain the area $A_{\min }$ from (11). All the other parameters can be calculated from the motor dimensions and magnetization $\mathrm{B}-\mathrm{H}$ data of the magnetic material. For better results, the area $A_{\max }$ can be precisely defined from (12) instead of (13), if the unsaturated inductance $L_{o a l}$ is measured or calculated. Also, if one magnetization $(\Psi-i)$ point in the saturation region at aligned position $\theta_{a l}$ is known, the parameter $\alpha$ in (21) can be set more precisely. If the magnetization $(\Psi-i)$ curves are known for some positions by measurements or numerical calculations, parameters $\xi, x_{1}, x_{2}, k_{a}$ and $y_{1}$ can be fitted for the best results.

\section{Dynamic Simulation Results}

Dynamic simulation results are obtained for the prototype 3 phase 6/4 SRM which parameters may be found in [1]. Simulation results of proposed method and of the Miller method [8] are compared in Fig. 4. The magnetization $(\Psi-i)$ curves from unaligned to aligned rotor position with step of $5^{\circ}$ are shown in Fig. 4. The energy conversion loops in Fig. 4 are obtained for the input control data given in Table I. For the sake of comparison Table I gives the simulation results of the proposed and the Miller [8] models, as well as results, found in [1], of the well known PC-SRD program package [15].

The new method is compared with method in [8] for a number of motors and results are in good agreement for one
TABLE I

COMPARISON OF SimUlation RESUlts of ThreE Methods

\begin{tabular}{c|c|c|c}
\hline Variable & Proposed & Miller [8] & PC-SRD \\
\hline DC supply voltage (V) & 24 & 24 & 24 \\
\hline Speed (rpm) & 2000 & 2000 & 2000 \\
\hline Tum on angle () & 47.5 & 47.5 & 47.5 \\
\hline Tum off angle ( ) & 80 & 80 & 80 \\
\hline Pesk phase current (A) & 26.316 & 27.473 & 26.193 \\
\hline Mean phisse current (A) & 7.919 & 8.192 & 7.916 \\
\hline Shaft power (W) & 271.826 & 274.638 & 261.17 \\
\hline
\end{tabular}

TABLE II

SOME PARAMETERS OF EXPERIMENTAL MOTOR

\begin{tabular}{c|c|c|c}
\hline Number of rotor poles & 4 & Stator outer diameter & $116 \mathrm{~mm}$ \\
\hline Number of stator poles & 6 & Stack Length & $48 \mathrm{~mm}$ \\
\hline Number of turns per pole & 590 & Stator pole height & $105 \mathrm{~mm}$ \\
\hline Stator pole arc & $32^{\circ}$ & Rotor pole height & $21 \mathrm{~mm}$ \\
\hline Rotor pole arc & $30^{\circ}$ & Shaft diameter & $19 \mathrm{~mm}$ \\
\hline Airgap length & $0.5 \mathrm{~mm}$ & Unaligned inductance & $48 \mathrm{mH}$ \\
\hline
\end{tabular}

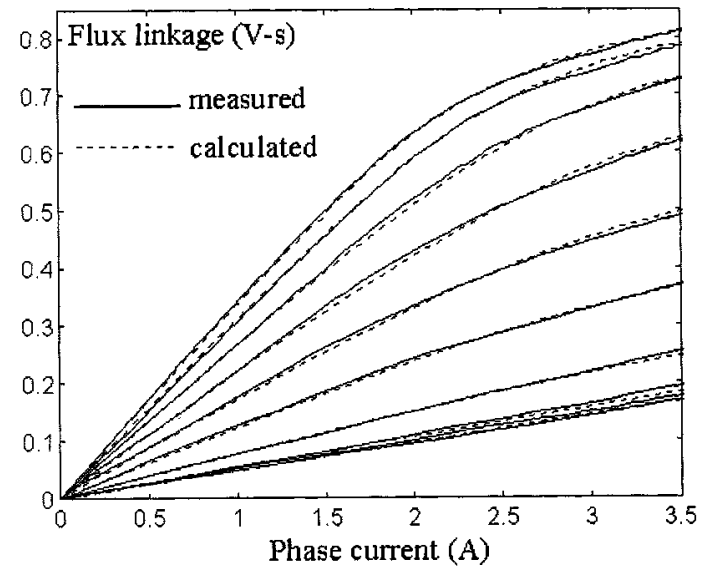

Fig. 5. Magnetization curves for experimental motor (from unaligned to aligned position with step $5^{\circ}$ of rotor position angle).

phase operations cases, which strengthen our confidence in proposed method.

\section{COMPARISON OF Simulation AND EXPERIMENTAL RESUltS}

For available three phase $6 / 4$ motor, with parameter given in Table II, we also performed the experimental measurements in order to compare them with simulation results of the proposed model.

The measured and the calculated magnetization curves of the motor from unaligned to aligned position with step of $5^{\circ}$ in the rotor position, are shown in Fig. 5. The results for static torque are compared in Fig. 6. Good agreements in Fig. 5, and in Fig. 6 are evident. The simulation results are obtained for nonfitted parameters in (18) and (20). As input data only two magnetization $(\Psi-i)$ points are used. One, which define unaligned inductance $L_{u n}$, is used for determining area $A_{\min }$ from (11), and another, highly saturated point at aligned position $\theta_{a l}$, for precise determining constant $\alpha$ in (20). All the other parameters 


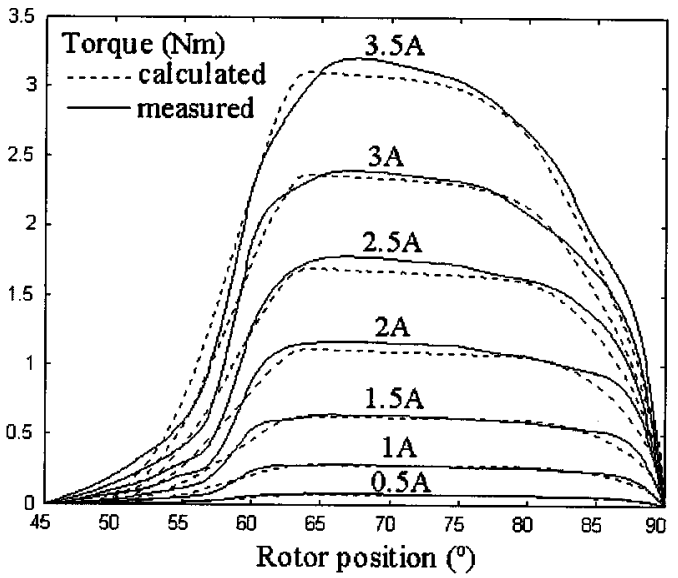

Fig. 6. Measured and computed static torque vs. rotor position angle for the motor with parameters given in Table II.

are calculated from motor geometry, from B-H characteristics of the used iron, or they are taken as empirical values.

\section{CONCLUSION}

In this paper a simple and effective model of the SRM has been presented. It can include all the important effects inherent to the SRM. As input, the model requires the main motor geometry, number of turns, some characteristics of the used magnetic material, and only one precalculated or measured magnetization $(\Psi-i)$ point. If some other magnetization points are known, the model allows correction of some parameters for more accuracy. Because of its features, the model is suitable to be used for CAD of SRM drives as support in searching for optimal motor geometry, optimal number of turns, choice of power converter topology and rating of semiconductors. The model gives good instantaneous shapes of current and torque, and, therefore, it may be used for optimization in control, as it is determination of optimal turn on and turn off angles in firing-angles control, shaping current waveforms for minimizing torque ripple or maximizing torque per ampere.

\section{REFERENCES}

[1] T. J. E. Miller, Switched Reluctance Motor and Their Control. Hillsboro/London, OH: Magna Physics Publishing/Oxford University Press, Hillsboro, 1993.

[2] D. W. J. Pulle, "New data base for switched reluctance drive simulation," IEEE Proceedings-B, vol. 138, no. 6, pp. 331-337, Nov. 1991.

[3] D. A. Torrey and J. H. Lang, "Modeling a nonlinear variable-reluctance motor drive," IEE Proceedings, pt. B, vol. 137, no. 5, pp. 314-326, Sept. 1990.
[4] W. M. Chan and W. F. Weldon, "Development of a simple nonlinear switched reluctance motor model using measured flux linkage data and curve fit," in IEEE IAS Annual Meeting, New Orleans, 1997.

[5] R. Arumugam, D. A. Lowther, R. Krishnan, and J. F. Lindsay, "Magnetic field analysis of a switched reluctance motor using a two dimensional finite element method," IEEE Trans. Magn., vol. May-21, pp. 1883-1885, Sept. 1985

[6] J. F. Lindsay, R. Arumugan, and R. Krishnan, "Finite-element analysis characterization of a switched reluctance motor with multitooth per stator pole," IEE Proc., pt. B, vol. 133, no. 6, pp. 347-353, Nov. 1986.

[7] A. M. Omekanda and M. Renglet, "Calculation of the electromagnetic parameters of a switched reluctance motor using an improved FEMBIEM-application to different models for the torque calculation," IEEE Trans. on Ind. Applic., vol. 33, no. 4, pp. 914-918, July/Aug. 1997.

[8] T. J. E. Miller and M. McGilp, "Nonlinear theory of the switched reluctance motor for rapid computer-aided design," IEE Proceedings, pt. B, vol. 137, no. 6, pp. 337-347, Nov. 1990.

[9] T. J. E. Miller, M. Glinka, M. McGilp, C. Cossar, G. Gallegos-Lopez, D. Ionel, and M. Olaru, "Ultra-fast model of the switched reluctance motor," in IEEE IAS, Annual Meeting, St. Luis, 1998

[10] A. M. Michaelides and C. Pollock, "Modeling and design of switched reluctance motors with two phases simultaneously excited," IEE Proc.-Electr. Power Appl., vol. 143, no. 5, pp. 361-370, Sept. 1996.

[11] P. Pillay, Y. Liu, W. Cai, and T. Sebastian, "Multiphase operation of switched reluctance motor drives," IEEE IAS, Annual Meeting, 1998.

[12] J. Faiz and J. W. Finch, "Aspects of design optimization for switched reluctance motors," IEEE Trans. on Energy Conversion, vol. 8, no. 4, pp. 704-713, Dec. 1993.

[13] A. V. Radun, "Design considerations for the switched reluctance motor," IEEE Trans. on Industry Applications, vol. 31, no. 5, pp. 1079-1087, Sept./Oct. 1995.

[14] J. W. Finch, "Magnetic permeance of aligned doubly salient structures," Correspondence, IEE Proceedings, pt. B, vol. 133, no. 6, pp. 365-366, Nov. 1986.

[15] PC-SRD User's Manual, 1992.

Vladan Vujičić received the B.S. and M.S. degrees in electrical engineering from the University of Montenegro, Podgorica, Yugoslavia, in 1993, and 1995, respectively.

$\mathrm{He}$ is currently a Teaching Assistant at the University of Montenegro and working toward Ph.D. degree in area of switched reluctance motor drives. His research interests include power electronic applications, variable speed drives and microprocessor control.

Slobodan N. Vukosavić received the B.S., M.S., and Ph.D. degrees in electrical engineering from the University of Belgrade, Belgrade, Yugoslavia, in 1985, 1987 , and 1989 , respectively.

Since 1986, he has been with "Nikola Tesla" Institute, Belgrade, leading research in the areas of power electronics and electrical drives. In 1988, joined ESCD Laboratory of Emerson Electric, St. Louis, MO, under the Cooperative Research Program in the field of switched reluctance motor drives and speed sensorless AC drives. From 1991, is with Vickers Electrics, Italy, organized and led the R/D team developing products for process automation and industrial robots. 